\title{
Technical Writing Pedagogy and Empathetic Medical Intervention: Using Design Thinking to Teach Wholistic Patient Care \\ Timothy Ponce, PhD
}

When my nursing students walk into the first day of my Introduction to Technical Writing course at the University of Texas Arlington (UTA), many come with assumptions about the content of the class and its purpose within the nursing curriculum. The infographics, graphs, tables, ordered lists, and data visualizations from their nursing textbooks swirl in their minds as they take their seat. After the

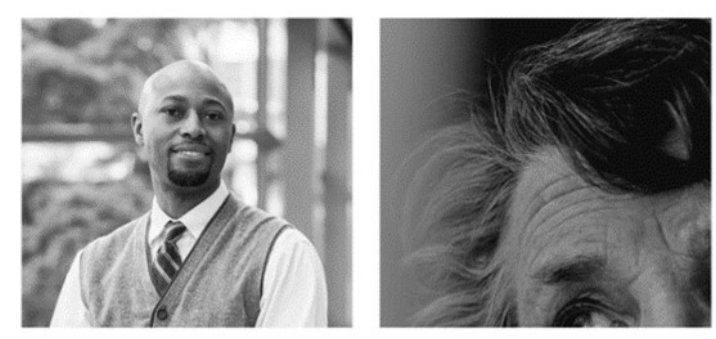
NEVER FOR GET YO UR U S E R
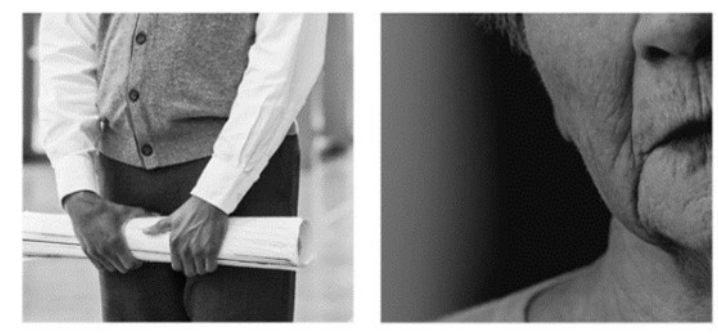

Figure 1: Visualization to emphasize the humanity of the user Photos licensed from Envato Elements standard pleasantries and first day introductions, I project the collage from figure 1 on the main screen to begin addressing my student's assumptions about technical writing.

Rather than starting with best practices for communicating complex information, one of the primary aims of technical writing, I instead begin with the human receiving that information-the "user" in technical communication parlance. "This course will focus on meeting the needs of users, users that possess mission critical knowledge you lack," I announce while confused students look on, wondering where all the pie charts and data tables went. The confusion created by the inclusion of a human variable amid a topic they assumed was based solely on facts, figures, and procedures extends, however, beyond their technical writing class.

In recent years, more and more health professionals have called for a wholistic approach to medical care, seeing psychological and emotional needs as vital variables to consider when crafting medical interventions. While some have tied the concern for wholistic care to a religious zeitgeist (Luk et al., 2007; Schuster, 1997; Ziebarth, 2016), others have more broadly considered its importance, calling for both primary and continuing medical education to include training on wholistic care (Booth \& Kaylor, 2018; Kulla \& Slettebø, 2020; Willis \& Leone-Sheehan, 2019). These calls to see the whole person sitting on the examination table, to create a partnership between medical professional and patient, parallels the user emphasis found in technical communication, particularly for those technical communicators that ascribe to design thinking, a heuristic that emphasizes a partnership between subject matter expert and user. In this article, I will explain how I teach design thinking to the aspiring medical professionals in my Introduction to Technical Writing class to help reinforce the importance of wholistic, empathetic, and patient-centered medical care, concluding with practical suggestions of how educators can implement a design thinking pedagogy in their courses, regardless of discipline.

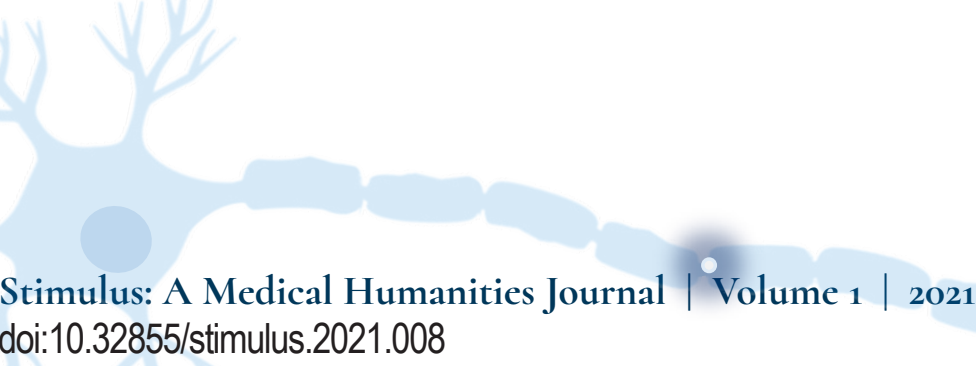




\section{Technical Communication Pedagogy, Design Thinking, and Wholistic Care}

While all theoretical approaches to technical communication share a focus on the end user, the layperson on the other end of the communication experience, few schools of thought in the milieux of technical communication emphasize the user as heavily as the Scandinavian cooperative design models, or design thinking, developed as part of the Utopia Project. Starting from roots in Norway in the early 1970s and fleshed out a decade later as part of the Utopia Project, cooperative design heuristics teach that the end user is not merely a passive receiver of information but rather a valuable partner in developing the strongest designs.

While the origins of cooperative design may have begun as a regional movement in Europe, its core mission to empower the user as an active and vital member of a production team has made worldwide impact (Bødker et al., 2020; Sundblad, 2008). This prolific impact stems from the components of design thinking, which utilizes the heuristic found in figure 2. Unlike linear, top-down problem-solution models, design thinking, to borrow terminology from Arne Van Oosterom, senior

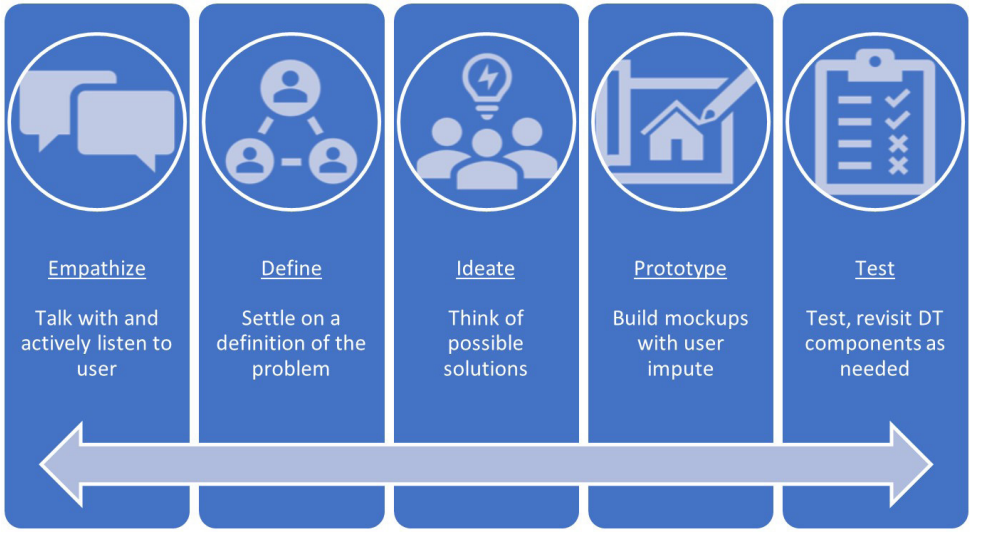

Figure 2: Components of Design Thinking partner and founder of Designthinkers Group, is a "mindset" in which the user is part of the problem-solving team rather than a mere recipient of a solution (Allen, 2017). As subject matter experts (SMEs) partner with users through the five design thinking components (figure 2), they combine their expertise with the user's experience and perspective to produce a stronger intervention than those created without the input of the user. This partnership between SME and user mirrors the spirit and practices of wholistic care.

While the term "wholistic care" remains nebulous and subjective, most agree that the practice, in general, centers on an attempt to meet the patient's physical, mental, emotional, and spiritual needs through patient-centered care, a biopsychosocial framework that leads to stronger medical outcomes (Bullington \& Fagerberg, 2013; Strandberg et al., 2007). The concept of wholistic care and patient-centered care are so interconnected that a 2017 study found the terms were used interchangeably by participants (Jasemi et al.). This practice of achieving better health outcomes through a therapeutic alliance between provider and patient mirrors the partnership between technical communicator and user emphasized in design thinking. Just as the technical communicator and user journey together toward the most effective communication experience (e.g., form, website, mobile application, manual, instructions), similarly providers and patients partner in crafting a wholistic medical intervention that contextualizes the expertise of the provider within the experiential knowledge of the patient. To help my aspiring medical professionals inculcate this cooperative mindset, I utilize a design thinking framework in my Introduction to Technical Writing course. 


\section{Design Thinking for Aspiring Medical Professionals in the Technical Communication Classroom and Beyond}

UTA is home to one of the nation's largest and most successful nursing schools, offering Commission on Collegiate Nursing Education certified degrees at the baccalaureate, masters, and doctoral level. The undergraduate program, which was one of nine programs out of 100 to be recognized as "high-achieving" by the Texas Higher Education Coordinating Board, requires every nursing candidate to successfully complete Introduction to Technical Writing before they can apply for admission to the nursing program itself. As a result, UTA Introduction to Technical Writing courses tend to attract primarily "pre-nursing" students. Given medical professionals' need for concise, precise, and clear communication, the UTA College of Nursing and Health Innovation's technical writing requirement aligns with the writing skills needed for professional success. This professionalization alone makes the course highly valuable, yet teaching the framework of design thinking, with its parallels to wholistic, patient-centered care, makes the course even more so. And while scholars such as Jason Tham have explored the benefits of design thinking's user focus in the technical writing classroom, the benefits that such a framework offers to aspiring medical professionals has yet to be discussed (2020).

To introduce the cooperative frame of mind associated with design thinking, I partner with the UTA FabLab, a maker space housed in the UTA Central Library. Similar to scholars such as Estee Beck, who explores the impact such a space has within multimodal composition (2020), I walk my students through an iterative design process utilizing the equipment in the maker space. I design my course project, which I schedule at the end of the first unit in the course, to highlight the mission critical information possessed by the user.

To begin the project, I divide my nursing students into groups of three and deliver a week of instruction in vector graphic creation. On the last day of exercises, I inform each group that they have received a request from a fictional home health agency-played by me-to create a logo, one that embodies the brand of the company. Once the logo receives approval from the company, each group must then use the logo to create a branded promotional item (mug, hat, 3D printed object, etc.) that would be enjoyed by their clients.

Without much hesitation, my students typically jump right in, sketching possible logos and thinking of the kinds of promotional items they can make with the equipment in the UTA FabLab. About ten to fifteen minutes into the project, though, they realize that the only information they are using to inform their logo design is a company name that I said out loud. They know nothing of the corporate culture, location of the company, or its primary patient demographic. The previous week of course instruction in the finer points of vector graphic design was not enough to produce a successful product. In other words, for all their subject matter expertise, they do not have the mission critical contextual knowledge, something possessed only by their client. After hitting this intellectual hurdle, I suggest that each group compose a message to their client requesting additional information. This message kicks off a dialogue between the group and their client, with groups combining the client's contextual knowledge with their subject matter expertise. 
After each group receives logo approval, they begin the difficult task of matching the spirit of the company to a physical object, something they have only assessed through a few emails. Once again, my students hit a purposefully placed problem. Just as reading data from an electronic health record can only provide a small window into a patient's needs, so also the general email exchanges they have sent to their client up to this point prove to be too limited to offer the wholistic perspective they need. Through coaching from me, the groups begin to ask more specific questions about the spirit of the organization, the experience of the patients, and many other "human" elements left out of previous exchanges. This again demonstrates the importance of a partnership between user and SME.

The final projects - which have ranged from a shaker cup for a company working with athletes to a laser cut wood puzzle for one working with children-act as a physical testimony to the importance of a cooperative mindset. Whether creating a logo or developing a care plan, SMEs only possess a portion of the knowledge needed to create the most effective intervention. To maximize potential, content area experts and users must partner together, with each seeing the other as a vital member of a team headed toward a shared goal.

While design thinking may be associated with technical communication and design, its cooperative frame of mind can be used in a variety of courses to help aspiring medical professionals to hone their wholistic approach to patient-centered care. The following are easy ways to integrate design thinking into your class:

1. Create Opportunities for Design Thinking: When constructing courses and assignments, try to make space for multiple drafts or iterations of a project. This offers students the opportunity to practice actively listening and responding appropriately: the foundation of any cooperative partnership.

2. Incorporate Service-Learning: While some see "service-learning" and think "volunteerism," the two are quite different. Service-learning is marked by reciprocity in which both community partner and student obtain value. By partnering with a community partner for a service-learning project, you enable your students to engage the components of design thinking - empathize, ideate, design, prototype, and test-all with a live partner. For more on service-learning in the medical classroom, see Groh, Stallwood, and Daniels (2011).

3. Embrace Cooperative Design in Your Own Course Development: Instructors at the collegiate level may be SMEs in their field, but the students in our courses possess a contextual knowledge that we lack. Dialogue with your students about the course design, making changes that maintain course integrity yet enhance your ability to reach course outcomes by contextualizing your expertise.

The cooperative spirit of design thinking can be used in any course to help students develop a mental framework that emphasizes equity, inclusion, and partnership. It takes traditionally privileged forms of knowledge and shows how, in isolation, they are insufficient to produce optimum outcomes. For my aspiring medical professionals, teaching this frame of mind in one of their first courses prepares them to be empathetically engaged, patient-centered practitioners who partner with their patient, contextualizing their subject matter expertise within the mission-critical knowledge of the human sitting on the exam table. 


\section{References}

Allen, T. (Host). (2017, June 27). Arne van Oosterom on the meaning of design thinking, purpose \& the art of innovation (No. 29) [Audio podcast episode]. In Impact Boom. https://www.impactboom.org/blog/2017/6/13/ arne-van-oosterom-on-the-meaning-of-design-thinking-purpose-the-art-of-innovation

Beck, E. (2020). Discovering maker literacies: Tinkering with a constructionist approach and maker competencies. Computers and Composition, 58(2020). https://doi.org/10.1016/j.compcom.2020.102604.

Booth, L., \& Kaylor, S. (2018). Teaching Spiritual Care Within Nursing Education: A Holistic Approach. Holistic Nursing Practice, 32(4), 177-181. https://doi-org.ezproxy.uta.edu/10.1097/HNP.0000000000000271

Bødker, S., Ehn P., Sjögren, D., \& Sundblad, Y. (2000, October) Co-operative design-perspectives on 20 years with 'the Scandinavian IT Design Model' [Keynote Address]. NordiCHI 2000, Stockholm. https://www. researchgate.net/publication/237225075_Cooperative_Design_-_perspectives_on_20_years_with_'the_Scandinavian_IT_Design_Model

Bullington, J., \& Fagerberg, I. (2013). The fuzzy concept of 'holistic care': a critical examination. Scandinavian Journal of Caring Sciences, 27(3), 493-494. https://doi.org/10.1111/scs. 12053

Groh, C. J., Stallwood, L. G., \& Daniels, J. J. (2011). Service learning in nursing education: Its impact on leadership and social justice. Nursing Education Perspectives, 32(6), 400-405.

Jasemi, M., Valizadeh, L., Zamanzadeh, V., \& Keogh, B. (2017). A concept analysis of holistic care by hybrid model. Indian Journal of Palliative Care, 23(1), 71-80. https://doi.org/10.4103/0973-1075.197960

Kulla, G., \& Slettebø, A. (2020). Dannelse og samskaping av utdanning mellom akademia og sykehjem. Nordic Magazine for Health Research, 16(2), 1-19. https://doi-org.ezproxy.uta.edu/10.7557/14.5199

Luk, A. L., Kwong, E. C. W., Wong, F. K. Y., \& Tsang E. S. W. (2007). A review of the concept of spirituality and spiritual assessment tools in Chinese context. Macau Journal of Nursing, 6(2), 23-19.

Schuster J. (1997). Wholistic care: Healing a "sick" system. Nursing Management, 28(6), 56-60. https://doiorg.ezproxy.uta.edu/10.1097/00006247-199706010-00017

Strandberg, E. L., Ovhed, I., Borgquist, L., \& Wilhelmsson, S. (2007). The perceived meaning of a (w)holistic view among general practitioners and district nurses in Swedish primary care: A qualitative study. BMC family practice, 8, 8. https://doi.org/10.1186/1471-2296-8-8

Sundblad, Y. (2008). From Utopia 1981 to Utopia 2008. In T. Binder, J. Löwgren, \& L. Malmborg (Eds.), (Re) searching the Digital Bauhaus (pp. 13-41). Springer.

Tham, J. C. K. (2020). Engaging design thinking and making in technical and professional communication pedagogy. Technical Communication Quarterly, 1-18.

Willis, D. G., \& Leone-Sheehan, D. M. (2019). Spiritual knowing: Another pattern of knowing in the discipline. Advances in Nursing Science, 42(1), 58-68. https://doi-org.ezproxy.uta.edu/10.1097/ANS.0000000000000236

Ziebarth, D. (2016). Wholistic health care: Evolutionary conceptual analysis. Journal of Religion \& Health, 55(5), 1800-1823. https://doi-org.ezproxy.uta.edu/10.1007/s10943-016-0199-6 